\title{
Meta
}

Journal des traducteurs

Translators' Journal

\section{Ingmar Bergman, maternidad y Franquismo: Traducción y censura de En el umbral de la vida}

\section{Rosario Garnemark}

Volume 57, numéro 2, juin 2012

La manipulation de la traduction audiovisuelle

The Manipulation of Audiovisual Translation

URI : https://id.erudit.org/iderudit/1013947ar

DOI : https://doi.org/10.7202/1013947ar

Aller au sommaire du numéro

Éditeur(s)

Les Presses de l’Université de Montréal

ISSN

0026-0452 (imprimé)

1492-1421 (numérique)

Découvrir la revue

Citer cet article

Garnemark, R. (2012). Ingmar Bergman, maternidad y Franquismo: Traducción y censura de En el umbral de la vida. Meta, 57(2), 310-324.

https://doi.org/10.7202/1013947ar
Résumé de l'article

La politique culturelle développée en Espagne pendant le régime franquiste (1939-1975) était caractérisée par un contrôle strict des répertoires culturels en circulation. Une manifestation très visible de ce protectionnisme culturel était l'établissement d'une censure d'État, qui réglait la production et la diffusion culturelles. En analysant les pratiques de censure étatiques dans En el umbral de la vida (Nära livet, 1958), d'Ingmar Bergman, notre article prétend contribuer à l'étude des façons de traduire de l'époque franquiste. S'inspirant du tournant culturel des études descriptives en traduction, et notamment des notions de mécénat et traduction comme réécriture, développées par Lefevere (1992), notre analyse veut montrer certains partis pris idéologiques qui guidaient la manipulation franquiste du discours filmique bergmanien. Tandis que l'original En el umbral de la vida présentait la maternité de façon ambigüe, la censure effaçait toute référence négative de ce film, favorisant ainsi le tendancieux discours franquiste sur ce phénomène.
Ce document est protégé par la loi sur le droit d'auteur. L'utilisation des services d’Érudit (y compris la reproduction) est assujettie à sa politique d'utilisation que vous pouvez consulter en ligne.

https://apropos.erudit.org/fr/usagers/politique-dutilisation/ 


\title{
Ingmar Bergman, maternidad y Franquismo: Traducción y censura de En el umbral de la vida
}

\author{
ROSARIO GARNEMARK \\ Universidad de Oslo, Oslo, Noruega \\ rosario.garnemark@ilos.uio.no
}

\begin{abstract}
RÉSUMÉ
La politique culturelle développée en Espagne pendant le régime franquiste (1939-1975) était caractérisée par un contrôle strict des répertoires culturels en circulation. Une manifestation très visible de ce protectionnisme culturel était l'établissement d'une censure d'État, qui réglait la production et la diffusion culturelles. En analysant les pratiques de censure étatiques dans En el umbral de la vida (Nära livet, 1958), d'Ingmar Bergman, notre article prétend contribuer à l'étude des façons de traduire de l'époque franquiste. S'inspirant du tournant culturel des études descriptives en traduction, et notamment des notions de mécénat et traduction comme réécriture, développées par Lefevere (1992), notre analyse veut montrer certains partis pris idéologiques qui guidaient la manipulation franquiste du discours filmique bergmanien. Tandis que l'original En el umbral de la vida présentait la maternité de façon ambigüe, la censure effaçait toute référence négative de ce film, favorisant ainsi le tendancieux discours franquiste sur ce phénomène.
\end{abstract}

\begin{abstract}
The cultural policies applied by the Spanish Francoist regime (1939-1975) aimed at exerting a strict control over all circulating repertoires. One of its most evident signs of protectionism was the establishment of an official state censorship body, in charge of supervising cultural production and dissemination. Through the analysis of censored fragments from the movie En el umbral de la vida (Nöra livet, 1958), by Ingmar Bergman, I will try to establish how censorship influenced translation practices at that time. Drawing on concepts derived from the cultural turn in Descriptive Translation Studies, namely patronage and translation as rewriting, developed by Lefevere (1992), I will try to establish what kind of ideological constraints influenced the Francoist manipulation of film discourse in this particular case. En el umbral de la vida portrays maternity in an ambiguous way. The intervention of censorship served here the purpose of erasing any negative reference depicted in the film, favoring instead the Francoist biased discourse about the issue of maternity.
\end{abstract}

\section{MOTS-CLÉS/ KEYWORDS}

censure, franquisme, Ingmar Bergman, doublage, traduction audiovisuelle censorship, francoism, Ingmar Bergman, dubbing, audiovisual translation

«Es posible que, en ciertos países, algunos retrasados mentales procuren cortar lo que ellos crean escandalizador».

Ingmar Bergman (Acerete 1965: 140)

En este artículo trataremos de establecer, mediante un análisis de la actividad traductora, cuáles fueron los condicionantes ideológicos que influyeron en la censura de la película sueca En el umbral de la vida (Nära livet, 1958), de Ingmar Bergman, 
durante la etapa franquista. Trataremos de demostrar cómo se manipuló el discurso en torno a la maternidad para adecuarlo al pensamiento patriarcal de la época. Para ello comenzaremos introduciendo brevemente algunos conceptos relevantes para nuestro estudio, recogidos del giro cultural adoptado por los Estudios Descriptivos de Traducción (EDT). Después indagaremos en la importancia de estudiar la censura como parte del sistema cultural franquista y en concreto en su impacto en la traducción. En tercer lugar, expondremos cómo se llevó a cabo la introducción de Ingmar Bergman en la España franquista. Finalmente, abordaremos el caso concreto de En el umbral de la vida y presentaremos nuestros análisis de varios fragmentos censurados, extraídos de una traducción A (traducción del guión presentado a censura) y una traducción B (subtítulos traducidos con marcas de censura).

Los EDT, surgidos en los años 1970, se basan principalmente en una concepción de la traducción como actividad comunicativa, regulada en primer lugar por la cultura receptora y su contexto histórico-social (Hermans 1985; Toury 1980; Delabastita 2006). Estas ideas están fundamentadas principalmente en la teoría de los polisistemas desarrollada por Even-Zohar (1990), según la cual la actividad traductora es primordial para el desarrollo de cualquier sistema cultural. Se establecen así una serie de relaciones de reciprocidad entre cultura y traducción que ven su apogeo en el llamado giro cultural, consagrado durante los años 1990 (Munday 2001: 125).

Uno de los primeros en adherirse a esta nueva corriente desde posturas polisistémicas fue Lefevere (1992: 2), quien analiza una serie de factores determinantes en la recepción de repertorios dentro de un sistema cultural, tales como el poder, la ideología, las instituciones o la manipulación. Todos estos factores influirán en la forma en que se reescriba un repertorio cultural para ser consumido en otra cultura diferente a la cultura de origen. La actividad traductora adquiere así el estatus de reescritura ideológica. Lefevere (1992: 15) describe una función de control dentro del sistema ejercida por «the powers (persons, institutions) that can further or hinder the reading, writing, and rewriting of literature», y que él denomina patronage (mecenazgo). El mecenazgo regula, según Lefevere (1992: 19), la balanza de poder entre la ideología imperante y las diversas poéticas circulantes. Una de las formas que puede adoptar es de vital importancia para nuestro estudio: la figura del censor.

\section{La censura franquista y la traducción}

El período de la historia de España denominado franquismo (1939-1975) se inicia tras la Guerra Civil española (1936-1939) con la victoria del General Francisco Franco, quien se alzó en armas junto con un grupo de militares contra el gobierno electo de la Segunda República. Franco logró unificar en su régimen a todas las fuerzas antirepublicanas bajo un único partido denominado Falange Española Tradicionalista y de las Juntas de Ofensiva Nacional Sindicalista. Esta fuerza política pasaría a integrarse más adelante en el denominado Movimiento Nacional, una especie de amalgama entre las instituciones franquistas y todas sus subideologías.

La administración de Franco se caracterizó en cuanto a política cultural por sus intentos de mantener un control estricto sobre los repertorios circulantes (Vandaele 2007: 280). Una de las manifestaciones más claras de este proteccionismo fue el establecimiento de un aparato oficial de censura estatal, que supervisó la "correcta» divulgación de todo tipo de expresiones artísticas, en especial el cine. ${ }^{1}$ Desde la 
creación en marzo de 1937 de una Junta de censura cinematográfica en las provincias de Sevilla y La Coruña hasta su abolición oficial en noviembre de 1977, la censura estatal cinematográfica pasó por distintas etapas de mayor o menor permisividad, de acuerdo con la orientación política e ideológica de las diferentes administraciones que se fueron alternando en el poder (Gutiérrez Lanza 2000: 57; Hurtley 2007: 87; Vandaele 2006: 78). El enfrentamiento quizás más claramente perceptible en el seno del aparato censor, como lo fue en otros niveles de la vida cultural y política durante toda la etapa franquista, fue el protagonizado por la Falange y la Iglesia católica en su afán por controlar el contenido de los discursos imperantes (Sevillano Calero 2003: 40, 49). La Falange contó desde el principio entre sus filas con personalidades atraídas por el mundo de las letras y la cultura, siempre desde un posicionamiento fascista, retomando de la tradición liberal culta aquello que le interesaba (Gracia 2004: 238), mientras que la Iglesia nacionalcatólica pretendía fundamentalmente proteger a España de la decadencia moral y espiritual en que había caído el resto del mundo occidental, sobre todo en materia sexual (Martínez Bretón 1987: 3, 102).

En lo que respecta a nuestro análisis, interesa destacar que en 1962 se produjo un relevo ministerial que trajo consigo un cierto aperturismo en materia de censura, al sustituir Manuel Fraga Iribarne al ultracatólico Gabriel Arias Salgado como Ministro de Información y Turismo. Este relevo supuso la evolución de un modelo de sociedad autárquica y ultracatólica, que había dado lugar a una censura oficial rígida e inmovilista (Gubern 1981: 171; Abellán 1980: 94), hacia otro modelo de corte industrial-capitalista, encomendado a un grupo de tecnócratas que debían sanear la economía española y estimular el turismo. A pesar de que seguía habiendo representantes del clero en las Juntas, rémora de la anterior etapa ultracatólica, los criterios de censura se vuelven más flexibles (Vandaele 2010: 87). La nueva imagen pública que España pretendía proyectar hacia el extranjero suponía enmascarar «sus aspectos más represivos y anacrónicos» (Gubern 1981: 181). Por razones estratégicas, España necesitaba convencer al resto del mundo de su capacidad de cambio: EvenZohar (1990: 22) ya planteó que el cambio en el seno de un sistema en determinadas circunstancias puede ser una maniobra de control.

En materia cultural, España trataba de modernizarse y ponerse a la altura de las tendencias occidentales. Gutiérrez Lanza (2002: 154) se refiere a este período de apertura cultural como «a mere imitation of foreign habits». En lo tocante a censura, la redacción del primer código oficial de censura (publicado en el BOE del 8 de marzo de 1963) supuso un gran avance desde el punto de vista jurídico, al poner en conocimiento de todas las personas físicas o jurídicas los principios que regían esta actividad (González Ballesteros 1981: 175). Sin embargo, numerosos sectores de la industria cinematográfica consideraron el código demasiado ambiguo y abierto a interpretaciones (Gutiérrez Lanza 2002: 154). Aunque las normas fueran públicas, la aplicación de las mismas quedaba sujeta al criterio y la interpretación de cada censor (Gutiérrez Lanza 2002: 154).

El estudio de las formas de censura aplicadas a la traducción resultará clave para entender los mecanismos por los que se regía el sistema cultural del franquismo. Como argumenta Vandaele (2010: 89), la actividad traductora representa en sí un ejercicio interpretativo en estado puro, del cual puede extraerse información de primera mano sobre los tipos de repertorios que se fomentan y los que no. Al mismo tiempo, la posición central de la traducción en el sistema cultural la vincula a todos 
los agentes que de algún modo producen, apoyan, propagan, obstaculizan o censuran textos (Hermans 1985: 237), lo que obliga a un estudio de la misma en conexión con todas estas actividades paralelas.

\section{La introducción de Ingmar Bergman en la España franquista}

La Introducción al estudio de Ingmar Bergman, de Fernández Cuenca (1961), se abre con una presentación del libro redactada por Antolín Santiago Juárez, Director de la Semana Internacional de Cine Religioso y de Valores Humanos de Valladolid. En ella, Santiago Juárez afirma que Fernández Cuenca «fue cronológicamente el primer crítico español que penetró en el mundo apasionante de Ingmar Bergman» (Fernández Cuenca 1961: 5).

Fernández Cuenca sostiene desde un primer momento que el descubrimiento internacional de Bergman se fecha erróneamente en 1956, año en que su película Sonrisas de una noche de verano (Sommarnattens leende, 1955) recibe el Premio al Humor Poético en el Festival Internacional de Cannes. Según Fernández Cuenca (1961: 7-8), existían ciertos críticos iberoamericanos que ya eran conscientes de la importancia de la obra de Bergman cuando éste recibe el mencionado galardón, y el propio Fernández Cuenca acude a la cita de 1956 en Cannes habiendo podido visualizar ya una buena parte de la obra de Bergman en Iberoamérica.

Aunque Bergman escribió su primer guión en 1944 (Tortura [Hets], film dirigido por Alf Sjöberg) y dirigió su primera película en 1946 (Crisis [Kris]), la crítica cinematográfica española, encarnada en la figura de Fernández Cuenca, no entró en contacto con la obra de Bergman hasta el año 1955. Habrían de pasar otros cinco años antes de que llegara a las pantallas de España El séptimo sello (Det sjunde inseglet, 1956), proyectada en la V Semana Internacional de Cine Religioso y de Valores Humanos de Valladolid de 1960, donde fue premiada con el galardón supremo del certamen. La implicación de Fernández Cuenca y del jesuita y censor Carlos $\mathrm{M}^{\mathrm{a}}$ Staehlin en la introducción de Bergman en España, así como su intervención en la censura de sus primeras películas, han sido aceptadas por diversos autores y merecen por ello un estudio más amplio. Gubern (1981: 154) afirma por ejemplo que: «fueron muy alterados los diálogos originales de El séptimo sello, el primer film de Ingmar Bergman estrenado en España, cuya traducción y adaptación corrió a cargo de los funcionarios censores, padre Carlos $\mathrm{M}^{\mathrm{a}}$ Staehlin y Carlos Fernández Cuenca». Igualmente, Company abre su monografía sobre Bergman afirmando que su obra nos fue llegando

[...] desordenadamente y con importantes intervenciones censoras, tanto en las imágenes como en los diálogos donde la piadosa mano del padre Staehlin - introductor oficial de Bergman en España - hacía decir a los personajes cosas insospechadas. (Company 1990: 9-10)

El séptimo sello es uno de los films más representativos de la temática religiosa de Bergman (Söderbergh Widding 2008: 198-199), lo que explica que fuera el elegido para su lanzamiento oficial en España en una etapa de censura ultracatólica. El censor Staehlin, uno de los que más «han profundizado en el apasionante aspecto de las preocupaciones espirituales de Bergman» (Fernández Cuenca 1961: 21), favoreció así la creación de una imagen de Bergman que, según Company (1990: 10), se forjó: 
«aplicando siempre un mismo esquema crítico que podría resumirse en el siguiente enunciado: Ingmar Bergman, realizador metafísico y angustiado, a la búsqueda de Dios y de la Trascendencia».

La apertura vivida en todos los niveles de la sociedad española a partir del comienzo de los años 1960 tuvo también un impacto en las actividades censoras. Una de las más importantes figuras de este período fue José María García Escudero, Director General de Cinematografía y Teatro entre 1962 y 1967 y máximo responsable de las Juntas censoras. García Escudero, militar de origen falangista, muy religioso sin ser moralista fanático, era un gran conocedor del cine como expresión artística y contaba con el respeto del mundo académico de la época, encarnado por el Instituto de Investigaciones y Experiencias Cinematográficas/Escuela Oficial de Cine (Vandaele 2006: 76). Su consolidación como intelectual del cine se produce tras su participación en las I Conversaciones Cinematográficas de Salamanca en mayo de 1955, organizadas por el sindicato universitario falangista SEU, que canalizó ciertos posicionamientos críticos respecto de la producción cultural franquista oficial (Gubern 1981: 117-118). Las Conversaciones de Salamanca, que contaron con el apoyo de García Escudero y Fernández Cuenca, así como de un nutrido grupo de intelectuales de diversas filiaciones vinculados con el cine (Gracia 1996: 56), supusieron un intento de modernización de la industria fílmica relacionado con la introducción del estilo neorrealista, en el nivel tanto teórico como práctico (Equipo Reseña 1977: 176).

En el diario que mantuvo durante sus cinco años como Director General, García Escudero (1978: 55) escribió sobre Bergman: «había que traer este otro Bergman incluso vodevilesco - que, paradójicamente, da su sentido al Bergman casi de catequesis que nos habíamos inventado». Se marca así una ruptura con la imagen del Bergman místico que se había ido formando unos años antes durante la etapa ultracatólica. Figuras como García Escudero empiezan a interesarse por Bergman más allá de lo puramente religioso, acercándose más a las posturas críticas internacionales del momento que lo ensalzan ya como «autor». Como explica Company (1990: 10): «Bergman es un autor y este concepto - que parece haber sustituido al de Bergman religioso - resulta igualmente mistificador y tramposo». Algunos de los escritos del propio García Escudero (1961a; 1961b) en la revista especializada Film Ideal, dan cuenta asimismo de este culto al Bergman autor.

El caso que a continuación pasamos a analizar se refiere a las prácticas censoras de una de las Juntas de censura dirigidas por García Escudero durante la etapa aperturista, y puede servir para ilustrar el tipo de actividad que se desarrolló durante aquellos años de incipiente (aunque todavía muy limitada) expansión cultural.

\section{El caso de En el umbral de la vida}

La película En el umbral de la vida (Nära livet, 1958)² supuso la primera colaboración entre Ingmar Bergman y la escritora sueca Ulla Isaksson, autora de los dos relatos en los que está basado el guión (Det vänliga, värdiga y Det orubbliga, aparecidos en 1954), que es producto de una adaptación del propio Bergman. La historia se centra en las experiencias de tres mujeres que comparten habitación en una clínica de maternidad en Estocolmo a finales de los años 1950: Cecilia, Stina y Hjördis. Cecilia, ingresada en la clínica tras sufrir un aborto natural al comienzo de su embarazo, recibe visita de su marido, a quien le reprocha no haber mostrado la suficiente ilusión por la 
criatura que estaban esperando y le habla abiertamente de su insatisfacción matrimonial. Piensa que debe pasar su vida en soledad.

Más adelante conocemos a Stina, en avanzado estado de gestación y dichosa porque pronto va a ser madre. Su marido la visita y ambos hablan entusiasmados de sus planes para cuando nazca el bebé. Desgraciadamente el parto de Stina presenta complicaciones y el bebé no sobrevive, lo que la sume en una gran tristeza. La tercera protagonista es Hjördis, que ha sido ingresada en la clínica tras intentar provocarse un aborto. Vemos como Hjördis se pone en contacto con su amante, que no muestra demasiado interés y le insta volver a intentar deshacerse de la criatura en cuanto salga de la clínica. A pesar de las ayudas que la sociedad sueca presta a las madres solteras, Hjördis no quiere ser madre pues no se siente preparada para poder criar a un bebé por cuenta propia. En una conversación con Cecilia, Hjördis le explica que no se atreve a ponerse en contacto con sus padres por temor a que la rechacen por estar embarazada. Cecilia opina aun así que debe ponerles al tanto de su situación. Más adelante, cuando presencia el desplome de Stina por haber perdido a su hijo, Hjördis decide llamar a su madre y le cuenta que está embarazada. Su madre reacciona positivamente y Hjördis decide viajar de inmediato a su casa. En la última escena vemos como Cecilia accede a que su marido la visite.

Aunque la película refleja ciertos temas constantes en la obra de Bergman, como la muerte, la soledad, el aislamiento, la falta de comunicación en la pareja o la angustia existencial (Donner 1964: 23), la temática central gira en torno a la maternidad. El tema se aborda desde una perspectiva ambigua, alejada de moralismos que, a través de las vivencias personales de estas mujeres, pretende dar cuenta del amplio abanico de sentimientos que la maternidad les inspira. Como afirma Siclier (1962: 202): «Bergman vuelve a sí mismo al abandonar la moral social en beneficio de la simple moral individual humana, cuando deja de considerar la maternidad como una función, para examinarla como un fenómeno». Se plantea así la dicotomía entre maternidad como concepto social, con una función muy determinada según la escala de valores patriarcal $v s$. maternidad como fenómeno privado, poblado de percepciones contradictorias, tanto positivas como negativas. Veremos cómo la censura franquista trató de borrar todo rastro de este segundo polo.

\subsection{Primeros rastros de censura}

La primera censura de la película En el umbral de la vida puede ubicarse dentro del período aperturista mencionado anteriormente, ya que pasó por dos Juntas de censura en abril y septiembre de 1964 respectivamente. ${ }^{3}$ En la primera sesión de abril se autorizó su doblaje al español, con las adaptaciones que comentaremos más adelante, y en la segunda sesión de septiembre se comprobó la correcta aplicación de las adaptaciones y se aprobó la clasificación de «Autorizada para mayores de 18 años». Tras hacer un repaso de los asistentes a ambas sesiones, ${ }^{4}$ todos ellos citados en la red de actores sociales descrita por Vandaele (2006: 72-78), ${ }^{5}$ que persigue establecer qué tipos de perfiles censores se daban y cuáles eran sus posibles complicidades, podemos afirmar que las dos Juntas que valoraron la película en cuestión contaban con representantes de los dos grupos ideológicos predominantes en el sistema cultural franquista: fascistas/falangistas (García Escudero, Fernández Cuenca, Soria, Lamet) y ultracatólicos (Cebollada, Cano). Resulta interesante comprobar que las posibles 
divergencias que pudieran darse entre ambos grupos ideológicos no se manifestaron en este caso de forma muy abierta. Los comentarios vertidos por los censores, recogidos en el expediente consultado, reflejan que hubo desde el principio un consenso bastante claro sobre el mensaje que se pretendía transmitir con esta película. No podemos saber a ciencia cierta si este consenso se debió a que ciertos censores aperturistas decidieron apoyar lo que decía la mayoría simplemente para que la película pudiera proyectarse. En cualquier caso, es muy probable que todos compartieran visiones parecidas sobre la función social de la maternidad y su papel en la cosmogonía femenina, ya que la mentalidad patriarcal del régimen franquista reproducía una determinada visión de la mujer y su papel dentro de la familia, y como recogen Alberdi, Escario et al. (1996: 80), no sería hasta 1975 cuando «se suprimen de la legislación las fórmulas más tradicionales y discriminatorias que supeditaban a las mujeres y las equiparaban con los menores de edad». En su obra dedicada a la Sección Femenina, órgano de adoctrinamiento femenino de Falange, Gallego Méndez explica que

[d]esde la primera enseñanza de las niñas hasta el último de los cursos impartidos por la Sección Femenina, desde cualquier discurso religioso o político dirigido a la mujer hasta las leyes de distinto rango elaboradas por el Estado, todo, incluyendo los valores sociales y culturales del franquismo, respondían a una concepción de la mujer, cuya esencia era la maternidad. (Gallego Méndez 1983: 161)

Por su parte, Richmond (2003: 122) comenta que «Franco's mandate was a statement that women should be restored to the home, reinforcing the patriarchal authority of the regime via their roles as wives, mothers and home-makers».

El tinte ideológico que reflejan los comentarios de los censores durante la primera sesión de abril viene a confirmar la situación expuesta más arriba y es de gran valor para acometer el análisis de las estrategias aplicadas a la traducción. A pesar de no contar con los testimonios escritos de la totalidad de los catorce asistentes a la sesión, los ocho que se conservan (cuyos nombres se mencionan entre paréntesis en la cita siguiente) hacen referencia a los aspectos positivos (exaltación de la maternidad, condena del aborto), pero dan cuenta de una cierta crudeza en la presentación, que es necesario atenuar. Ofrecemos sus opiniones en bloque, para hacer hincapié en el consenso mostrado:

Un tema crudo pero claramente aleccionador pues es una condenación del aborto y una exaltación de la maternidad. (Florentino Soria)

Tres actitudes ante la propia maternidad. La chica frívola que siente el horror de ser madre, aprende en la clínica que ser madre es algo maravilloso. Creo que la película tiene una positiva lección ante un problema grave de la sociedad actual: el aborto. Deberían corregirse algunos defectos de estilo para que no fuera tan realista. (Manuel Villares)

Crudo realismo en la forma, pero fondo absolutamente moral y positivo en torno a la maternidad. Sin mayor problema que su exterior desagradable. (José Luis de Celis)

Film totalmente positivo por su cualidad de reactivo contra el aborto. Film, desde luego, desagradable en algunos aspectos, pero realizado con tacto y sensibilidad. Creo conveniente su proyección, especialmente por cuanto que, al parecer, el aborto empieza a ser usual en España. Me uno, finalmente, a la opinión de los sacerdotes de la Junta. (Juan Miguel Lamet) 
Es una película francamente positiva, aun reconociendo la intimidad de los temas y lo fuerte de algunos planos, inconvenientes que se pueden obviar suprimiendo algunos planos y suavizando algunas frases y palabras. (Miguel Cerezo)

El tema básico es la exaltación de la maternidad y por tanto la película debe aprobarse, aligerando únicamente alguna secuencia - el tremendo realismo del parto, del que puede cortarse algún plano -, y modificando alguna expresión del diálogo, según se señala en el acta general. (Elisa de Lara)

Sustitución de palabras duras por otras y supresión de algún plano formal violento. Con esas modificaciones la película quedará plenamente positiva, aunque a algún sector del público pueda parecer fuerte. Es importante su alegato contra el aborto. (Pascual Cebollada)

Película estrictamente para mayores: por tema, por clima, por situaciones; positiva y ejemplar. (Marcelo Arroita-Jáuregui)

La naturaleza de las imágenes suprimidas también resulta de gran interés para ilustrar las adaptaciones realizadas en la traducción. Éstos fueron los cortes aplicados en imágenes de acuerdo a lo decidido en la sesión de abril de 1964:

- Rollo 10: Suprimir plano de las sábanas ensangrentadas.

- Rollo 50: Suprimir receta del aborto.

- Rollo 70: Suprimir los dos planos de las piernas de Stina en el momento del parto, desde el punto de vista de ella.

- Rollo 8º Suprimir plano del pecho de la lactante.

En la siguiente sesión de septiembre de 1964, en la que se acordó por unanimidad clasificar la película como Autorizada para mayores de 18 años, tras comprobar que se habían aplicado los cambios y adaptaciones propuestos en la primera sesión, tan solo dos vocales realizaron anotaciones en sus informes, pues consideraban que debían realizarse más cortes en determinadas escenas:

Aunque no lo "hago cuestión de gabinete", y he firmado la hoja general de comprobación de doblaje, creo que, en pleno, debería reconsiderarse la escena del parto y abreviar más aún los espasmos de dolor, por los efectos contraproducentes que seguramente han de ocasionar a las madres jóvenes o que van a serlo, no por razones de orden moral, pues en ese aspecto no le encuentro reparo. (José $\mathrm{M}^{\mathrm{a}} \mathrm{Cano}$ )

Es una exaltación a la maternidad. Creo sin embargo que la escena del parto debería abreviarse. No considero esto, desde luego, por razones morales, pero sí creo es demasiado dura para mucha gente, y que puede producir en muchas mujeres que esperen niño psicosis de verdadero susto, no solo por la tremenda dureza del parto, sino también por que [sic] de tres mujeres que esperan niño, dos de ellas lo pierden, claro que cortar esto comprendo no se podría pero sí abreviar. (María Sampelayo)

Según consta en el Acta General, la propuesta de estos dos últimos vocales fue rehusada por el resto de los asistentes, lo que podría considerarse como una victoria simbólica de los aperturistas, teniendo en cuenta que Cano es uno de los censores de este período con un perfil más ultracatólico (Vandaele 2006: 77). Resultan interesantes también los comentarios de Sampelayo, una de las pocas mujeres que participaron en la censura estatal, que denotan hasta qué punto la visión patriarcal había calado en la sociedad franquista, siendo necesario proteger a otras madres jóvenes de ciertas realidades en torno a la maternidad. 
A continuación analizamos los cambios lingüísticos propuestos por la Junta de abril de 1964. Cabe señalar a este respecto que los censores contaban con una traducción preliminar del guión, a la que llamaremos traducción A. Este tipo de traducciones preliminares eran producidas por las distribuidoras cinematográficas como requisito para presentar las películas a censura. Los censores las utilizaban como herramienta de evaluación con motivo de la primera visualización de la película. Los cambios propuestos en este caso hacen referencia a la traducción preliminar del guión o traducción A con la que trabajaron los censores.

\section{CUAdRO 1}

Cambios lingüísticos propuestos por la Junta de abril de 1964

\begin{tabular}{|c|c|}
\hline $\begin{array}{l}\text { Términos/Expresiones empleados en la traducción A } \\
\text { Texto origen en sueco }^{6}\end{array}$ & $\begin{array}{l}\text { Cambios propuestos en el } \\
\text { expediente de censura }\end{array}$ \\
\hline $\begin{array}{l}\text { Sangre } \\
\text { Blod }\end{array}$ & Sustituir por hemorragia \\
\hline $\begin{array}{l}\text { Menstruación } \\
\text { Reglering }\end{array}$ & Sustituir por periodo \\
\hline $\begin{array}{l}\text { Panza } \\
\text { Mage }\end{array}$ & Sustituir por vientre \\
\hline $\begin{array}{l}\text { Ahora no es ni una vergüenza ni una desgracia para una chica esto } \\
\text { de tener un niño. } \\
\text { Det är varken någon skam eller en olycka för en flicka att få ett } \\
\text { barn nuförtiden. }\end{array}$ & Sustituir por No desesperes \\
\hline $\begin{array}{l}\text { Después de todo, no llegarán a ser [los bebés] más que una mierda. } \\
\text { De blir bara skit alltihop. }\end{array}$ & Suprimir mierda \\
\hline $\begin{array}{l}\text { Me había atiborrado de quinina, había bebido coñac y más coñac, } \\
\text { y había saltado a la comba ¡Todo lo que yo he brincado! } \\
\text { Käkat kinin och druckit konjak. Hoppat hoprep. Gud vad jag } \\
\text { hoppat! }\end{array}$ & $\begin{array}{l}\text { Suprimir todo el fragmento, } \\
\text { denominado por los censores } \\
\text { receta del aborto }\end{array}$ \\
\hline $\begin{array}{l}\text { Apuesto a que la culpa la tiene este puñetero niño. } \\
\text { Jag ger mig fan på att det är denna förbannade ungens fel. }\end{array}$ & Suprimir puñetero \\
\hline
\end{tabular}

Como ya vimos, Bergman plantea la maternidad de forma ambigua, incluso con ciertas connotaciones existenciales sobre la delgada línea que separa la vida de la muerte. Los comentarios de los censores demuestran que su propia visión de la maternidad se inclina más hacia lecturas de la misma como estado ideal de la mujer en su función de fundadora y soporte supremo de la familia. Por ello, la intervención de la censura va orientada a borrar cualquier referencia (incluso por medio de imágenes) que pudiera poner en entredicho la lectura de este fenómeno promovida por el franquismo. Queda atenuada así la posibilidad de un Bergman que, como nos dice Company:

[...] nos ha ido mostrando, a lo largo de su filmografía, fascinantes retratos de mujeres libres que en un momento determinado deciden cambiar sus vidas aunque ello suponga poner en crisis la razón patriarcal que hasta ahora las ha dominado. (Company 2008: 23)

El cuestionamiento de la razón patriarcal o la capacidad de libre elección de la mujer no parecían ser prioridades dentro de la agenda ideológica franquista. Por ello, había que aplicar una serie de adaptaciones que reorientaran posibles desviaciones del mensaje deseado. 
Analicemos uno por uno los cambios propuestos por los censores, ya que cada uno de ellos sirve para ilustrar la estrategia ideológica aplicada para rectificar el discurso. La sangre femenina, prueba definitiva de la realidad material del parto y portadora de posibles connotaciones negativas de dureza o dolor, no podía mostrarse en pantalla, ni podía hablarse de ella. Se propone así un término más aséptico, casi clínico (hemorragia). Similar tendencia encontramos en la propuesta de sustituir menstruación (de nuevo la referencia a la sangre) por periodo (un término más neutral, que hace referencia a un concepto más abstracto de ciclo). En el caso de panza estamos ante un término ligeramente peyorativo, en cualquier caso coloquial, que se sustituye por el más neutral vientre. Del mismo modo, referirse a la maternidad como una vergüenza o una desgracia, así como calificar a un bebé de mierda o de puñetero, era totalmente inaceptable para la visión edulcorada y casi espiritual que pretendían transmitir los censores de la maternidad. Por ello tales referencias debían suprimirse o alterarse drásticamente. El fragmento denominado por los censores como receta del aborto ejemplifica además la imposibilidad de nombrar realidades incómodas o impensables. Si la película tenía que entenderse como una condena del aborto, no podía mostrarse una protagonista que hablaba abiertamente de cómo había tratado de poner fin a su embarazo, aunque con ello se alterara totalmente su discurso. Junto a la intención moralizante de las medidas propuestas, existía además una actitud paternalista implícita en la ocultación o manipulación de la información. Los censores creían saber qué le convenía ver al público para poder llegar a entender la verdad (o su versión de la verdad) implícita en el film.

El mensaje fabricado por los censores condicionó la respuesta de la crítica y suscitó diversas reacciones. Molist (1965: 315, mi cursiva), en su reseña aparecida en la prestigiosa Film Ideal, se esfuerza en afirmar que: «la importancia que Bergman concede a la maternidad cuenta con claros antecedentes. [...] No debe sorprendernos, pues, que Bergman se enfrentase en esta obra con la primordial función femenina». Del texto original, sin embargo, no podemos deducir si Bergman considera la maternidad como función primordial de la mujer o no. En cualquier caso, la elección del adjetivo «primordial» para referirse a la maternidad es reveladora, por un lado, de que existe una visión muy determinada de la misma en la sociedad franquista y, por otro, de que la película censurada ha logrado transmitir y (re)producir esta escala de valores.

Otra reseña aparecida en el no 34 de la revista Cinestudio, gracias a la cual podemos saber que la película se estrenó el 17 de mayo de 1965 en el Cine Amaya de Madrid, es de talante más crítico, pero también refleja hasta qué punto se edulcoró la visión de la maternidad. El comentador en este caso, aunque se confiesa padre de familia numerosa, encuentra exagerado el tono simbólico y moralizante de la película y achaca a Bergman estos excesos de "didactismo», alejados de "la valentía de sus temas y la calidad intelectual de su cine» (Pérez Lozano 1965: 193). Posiblemente el crítico habría llegado a otras conclusiones si hubiera podido ver la versión sin censura, donde por ejemplo se hacían alusiones directas al aborto. En otra reseña firmada por Bilbatua (sin fecha y sin paginar, se trata de un recorte adjunto al expediente de censura) se denuncian los cortes realizados, lo que suscitó el envío por parte de García Escudero de una misiva de respuesta explicitando que «solo» se habían cortado 38 segundos de proyección. 


\subsection{Más rastros de censura}

En la Filmoteca Nacional de Madrid se encuentra una versión subtitulada de la película En el umbral de la vida en formato VHS, grabada directamente de una emisión televisiva, pero sin fecha exacta de emisión. No es posible saber si esta copia subtitulada es producto directo de una adaptación del doblaje censurado en 1964 o si se trata de nuevos subtítulos partiendo del texto origen sueco (o en otro idioma) y elaborados en una etapa posterior. No existe tampoco mención alguna en el expediente de censura que nos lleve a pensar que esta copia subtitulada fue supervisada por una Junta de censura de García Escudero. De haberse encargado subtítulos en su día, esto habría quedado reflejado de alguna manera en el expediente de censura correspondiente, que en el caso de esta película es muy completo. No obstante, podría tratarse de una versión subtitulada producida de forma paralela o posterior a la doblada para ser proyectada en Cine-clubs o Salas Especiales, por ser éstos los foros en los que se introdujo y permitió el uso de subtítulos, ${ }^{7}$ y rescatada más adelante por algún canal de TV. En cualquier caso, puede afirmarse que el proceso de traducción por el que se llega a estos subtítulos, a los que llamaremos traducción $\mathrm{B}$, recoge prácticamente la misma carga ideológica ya presente en los cambios aplicados por la censura sobre la traducción A. Retomaremos así los mismos fragmentos comentados con anterioridad, para establecer qué tratamiento se les dio en esta versión subtitulada.

En lo que respecta a los tres primeros ejemplos, los términos sangre, menstruación y panza no aparecen en los subtítulos y se respeta la decisión de los censores de 1964 de emplear hemorragia, periodo y vientre. En el fragmento en el que aparecían los términos vergüenza y desgracia se descarta la solución propuesta por los censores de 1964 (No desesperes), pero se evitan los términos de connotación negativa con el subtítulo Un hijo concebido ha de ser un estímulo, que incluye un término más positivo (estímulo). Y en la misma línea, el término mierda se sustituye por porquería, rebajando la carga negativa (el subtítulo empleado en este caso es Serán como nosotros, una verdadera porquería). El fragmento referente a la receta del aborto es un caso muy interesante. Forma parte de un diálogo en el que Hjördis relata a una amiga cómo intentó provocarse un aborto sin éxito, siendo ésta la razón por la que está ingresada en la clínica. En el doblaje de 1964 se decreta la eliminación de este fragmento, mientras que en la versión subtitulada se opta por traducir el diálogo alterando una parte clave de la conversación. Donde, en el texto sueco, la amiga pregunta ¿qué habías hecho [para provocarte el aborto]?, en la versión subtitulada la pregunta se convierte en un ¿qué habrías hecho?, lo que nos reenvía a una parte anterior de la conversación en la que Hjördis le confiesa a su amiga que hubiera preferido no ir a trabajar, ya que no habría acabado en la clínica si sus compañeros de trabajo no la hubieran llevado allí. Con una simple alteración del tiempo verbal (habrías por habías) la pregunta ya no hace referencia a lo que había hecho para que la llevaran a la clínica (intentar provocarse un aborto), sino a lo que Hjördis habría hecho si no hubiera ido a trabajar, perdiendo así toda referencia al intento de aborto. La respuesta inventada por los censores fue Ni yo misma lo sé, atiborrarme de coñac, todo menos esto. Es interesante destacar que se ha guardado el vocablo coñac en los subtítulos, aunque el contexto en el que se emplea sea totalmente diferente (causante del aborto en la versión original; simple pasatiempo como alternativa a acudir al trabajo en la versión censurada). Esto podría deberse a que el traductor de los subtítulos se hubiera percatado de que konjak en sueco y coñac en español son bastante similares fonéti- 
camente, al tratarse en ambos casos de un préstamo francés. Puesto que existía una conciencia crítica por parte del público y la prensa sobre las actividades de la censura, es posible que el traductor tratara de cubrirse así las espaldas frente a posibles polémicas. Si el público de la versión subtitulada era capaz de distinguir la mención a konjak pronunciada por la actriz en la banda sonora original sueca, era importante que el equivalente español apareciera reflejado en los subtítulos. En el último ejemplo se vuelve a favorecer la estrategia de eliminación y el término sueco förbannade (puñetero) desaparece (el subtítulo empleado fue Seguro que es todo por este niño).

Además de estos casos censurados, se pueden detectar al menos dos fragmentos más de la traducción B sujetos a censura. Ambos forman parte de la trama en torno a Stina, la madre en avanzado estado de gestación que pierde a su hijo por complicaciones en el parto. Ella y su marido son presentados como la pareja ideal, colmados de alegría por la próxima llegada de su bebé. Representan el modelo de familia patriarcal promovido por el franquismo y por ello su actitud debe ser intachable. El primer ejemplo censurado pertenece al discurso de Stina antes de perder a su hijo:

CUADRO 2

Marcas de censura extra-oficiales en la traducción B; ejemplo 1

\begin{tabular}{|l|l|}
\hline Texto origen en sueco & Traducción B \\
\hline Jag ska se till att han blir döpt i kyrkan i alla fall. Fast Harry är & A ver si convenzo a Harry para \\
inte riktigt med på det. Harry, han är den bästa i världen för & que le bauticen aquí [en la \\
mig, men sådant här begriper han inte riktigt. & clínica]. No está muy de \\
[Me aseguraré de que le bauticen en la iglesia en cualquier caso. & acuerdo. Es el mejor hombre \\
Aunque Harry no está del todo de acuerdo. Harry, él es el mejor & del mundo, pero muy \\
del mundo para mí, pero estas cosas no las entiende del todo.] & testarudo. \\
\hline
\end{tabular}

El texto sueco da a entender que el marido de Stina y futuro padre de la criatura no es creyente, $\mathrm{o}$ al menos practicante. La censura aplicada a la traducción $\mathrm{B}$ ha borrado esta referencia, que habría puesto en peligro la imagen de marido y padre perfecto sustentada en el imaginario franquista. Hacerle pasar por alguien testarudo por no querer que su hijo sea bautizado directamente en la clínica es mucho menos grave que mostrarle tal y como aparece en el texto origen, es decir, como alguien que directamente descarta el bautizo.

El segundo ejemplo hace referencia a un momento posterior en el desenlace de la trama, en el que Stina ya ha perdido a su hijo. Se trata de la explicación ofrecida por el médico que la ha atendido durante el parto sobre las causas de la muerte del bebé:

\section{CUADRO 3}

Marcas de censura extra-oficiales en la traducción B; ejemplo 2

\begin{tabular}{|l|l|}
\hline Texto origen en sueco & Traducción B \\
\hline $\begin{array}{l}\text { Jag står lika hjälplös som ni, fru Andersson. Och jag beklagar } \\
\text { det med hela mitt hjärta. Det var inget fel på er, och så vitt vi } \\
\text { kunnat se, var det inte något fel på pojken heller. Men livet ville }\end{array}$ & $\begin{array}{l}\text { Lo siento tanto como usted. El } \\
\text { niño y usted estaban bien, pero } \\
\text { Dios no quiso que viera el } \\
\text { inte, fru Andersson. Hur grymt det kan tyckas. Det är det enda } \\
\text { jug kan säga. }\end{array}$ \\
$\begin{array}{l}\text { [Me siento tan impotente como usted, Sra. Andersson. Y lo que le puedo } \\
\text { decir. Resignación, Sra. }\end{array}$ \\
$\begin{array}{l}\text { Andento con todo mi corazón. No había ningún problema con } \\
\text { usted y, por lo que hemos podido ver, tampoco había ningún } \\
\text { problema con el niño. Pero la vida no quiso, Sra. Andersson. Por } \\
\text { muy cruel que pueda parecer. Es lo único que puedo decir.] }\end{array}$ \\
\hline
\end{tabular}


Lo que llama la atención es la referencia añadida a Dios como responsable de la muerte de la criatura en la versión censurada, lo que impide en un contexto franquista definir la situación como cruel, tal y como se enuncia en el diálogo sueco. Al convertir la muerte en un acto divino, resulta natural desde el enfoque nacionalcatólico que el médico le pida a la paciente resignación, algo que no se menciona en ningún momento en el texto origen y que, por otro lado, contribuye a reforzar una de las cualidades definitorias de la mujer según el ideario franquista. El acto biológico (y por ello ambiguo, abierto a un desenlace negativo) de dar a luz se convierte en una vivencia semi-espiritual, regida por una fuerza superior que podría entenderse como una negación de la interpretación darwiniana de la creación.

En esta versión subtitulada, además de censurarse los mismos fragmentos que en el doblaje de 1964, se encuentran también marcas de censura en otros fragmentos que no se recogían en el informe oficial de 1964, lo que bien podría ser fruto de una censura paralela o posterior no documentada o de la propia iniciativa del traductor. Las tensiones ideológicas de la época franquista, con el aparato censor como garante de la moralidad, lograron inculcar unas prácticas traductoras muy mediatizadas por el tipo de discurso aceptado y aceptable. En este sentido, no es de extrañar que los traductores, por obligación, por hábito o por convicción propia, aplicaran estrategias orientadas a reescribir los discursos que pudieran resultar problemáticos.

\section{Conclusión}

La figura del mecenazgo, encarnada fundamentalmente en la Junta de censura y clasificación cinematográfica, ejerció a través de sus decisiones una influencia directa en la traducción de la película En el umbral de la vida. El análisis de una serie de ejemplos concretos ha contribuido a demostrar cómo, en el proceso de traducción, el texto fue reescrito para adecuarse a la ideología patriarcal franquista, con especial hincapié en el discurso sobre la maternidad. Igualmente, una copia censurada posterior de difícil clasificación cronológica, nos ha permitido demostrar cómo los traductores, por coerción o por cuenta propia, tendieron a reproducir el mismo tipo de ideología, acudiendo incluso a estrategias que realzan el valor religioso del texto para presentar la maternidad como una especie de don divino. La censura oficial de esta película, a pesar de realizarse durante una etapa aperturista, contribuyó a la distorsión de los personajes mediante la manipulación de sus discursos, algo que fue retomado en la copia subtitulada posterior. El resultado fue la presentación en las pantallas españolas de un Bergman reescrito con el fin de adaptarlo a la agenda religiosa y moral del franquismo.

\section{AGRADECIMIENTOS}

La autora desea expresar su más sincero agradecimiento a Jeroen Vandaele y Cecilia Alvstad, de la Universidad de Oslo, por su ayuda y apoyo durante la redacción de este artículo.

\section{NOTAS}

1. También existió una censura fílmica eclesiástica de carácter orientativo, paralela a la censura estatal, que aplicó su propio sistema de clasificación de películas durante toda la etapa franquista con una línea moralista clara y constante (Gutiérrez Lanza 2000: 57).

2. Para una ficha filmográfica completa de la película véase <www.ingmarbergman.se/castcredits. asp?guid=AEF41787-29E6-4DB5-A3A1-A5745FBED134>, consultada el 29 de abril de 2010. Cabe 
mencionar que esta película fue galardonada en el Festival de Cannes de 1958 con el premio al mejor director, al mejor guión y a la mejor interpretación femenina conjunta para las cuatro actrices principales.

3. Toda la información ofrecida a continuación sobre el expediente de censura de esta película puede consultarse en la entrada 36/04053 de la base de datos IDD (03)121.002, custodiada en el Archivo General de la Administración (AGA), en Alcalá de Henares.

4. Sesión de abril: José Ma García Escudero (Presidente), Florentino Soria (Vicepresidente), Manuel Andrés Zabala, José Luis de Celis, Miguel Cerezo, Elisa de Lara, Pascual Cebollada, Marcelo Arroita-Jáuregui, Guillermo de Reyna, Juan Miguel Lamet, José Ma Cano (Vocales), Luis G. Fierro, Manuel Villares (Vocales eclesiásticos), Sebastián Bautista de la Torre (Secretario).

Sesión de septiembre: Manuel Andrés Zabala (Vicepresidente), María Sampelayo, Luis Ayuso, Carlos Fernández Cuenca, José Ma Cano, Marcelo Arroita-Jáuregui, Víctor Aúz (Vocales), César Vaca, Manuel Villares, Luis Fierro (Vocales eclesiásticos), Sebastián Bautista de la Torre (Secretario).

5. Con excepción del Secretario de ambas sesiones, Sebastián Bautista de la Torre; sí aparece sin embargo en la enumeración de Vandaele un tal Joaquín Bautista de la Torre, probablemente relacionado por parentesco directo con el anterior.

6. Nuestro estudio de los expedientes de censura correspondientes a otras películas de Ingmar Bergman nos ha demostrado que la traducción indirecta a través de lenguas intermedias más comunes que el sueco era una práctica relativamente habitual, y en ciertos casos abiertamente documentada. En esta película en concreto no podemos saber a ciencia cierta si esta traducción se realizó directamente de la versión sueca o si se empleó una lengua intermedia, ya que no hay anotación alguna al respecto. No obstante, hemos optado por incluir el texto origen en sueco por considerar que la traducción presentada no presenta divergencias significativas respecto de éste.

7. Aunque el doblaje se impuso como única práctica posible por Orden Ministerial en 1941 (Gutiérrez Lanza 2002: 158; Vandaele 2010: 99), la derogación de esta Orden en 1946 dio paso a un uso muy limitado de subtítulos para películas proyectadas en Cine-clubs, asociaciones para miembros establecidas en 1951 (Vandaele 2010: 99-100), o en las llamadas Salas Especiales o Salas de Arte y Ensayo, con un aforo máximo de 500 espectadores y creadas en 1967 en ciudades con una población superior a 50.000 personas (Gutiérrez Lanza 2002: 154).

\section{REFERENCIAS BIBLIOGRÁFICAS}

Abellán, Manuel (1980): Censura y creación literaria en España (1939-1976). Barcelona: Península.

Acerete, Julio C. (1965): El séptimo sello. Barcelona: Aymá.

Alberdi, Inés, Escario, Pilar y López-Accotto, Ana Inés (1996): Lo personal es político. El Movimiento Feminista en la Transición. Madrid: Instituto de la Mujer.

Bilbatua, Miguel (sin fecha): Una película falseada. "En el umbral de la vida", de Ingmar Bergman. Signo. 402: sin paginar.

Company, Juan Miguel (1990): Ingmar Bergman. Madrid: Cátedra.

Company, Juan Miguel (2008): Ernst Ingmar Bergman Akerblom (1918-2007): apuntes biográficos y textuales. In: Pedro Jesús Teruel Ruiz y Ángel Pablo Cano Gómez, eds. Ingmar Bergman, buscador de perlas. Cine y filosofía en la obra de un maestro del Siglo XX. Murcia: Morphos Ediciones, 17-26.

Delabastita, Dirk, ed. (2006): Functional Approaches to Culture and Translation: Selected Papers by Jose Lambert. Ámsterdam: John Benjamin.

Donner, Jörn (1964): The Personal Vision of Ingmar Bergman. Bloomington: Indiana University Press.

EQUipo Reseña (1977): La cultura española durante el franquismo. Bilbao: Mensajero.

Even-Zohar, Itamar (1990): Polysystem Studies. (Special issue). Poetics Today. 11(1).

Fernández Cuenca, Carlos (1961): Introducción al estudio de Ingmar Bergman. Madrid: Filmoteca Nacional de España.

Gallego Méndez, María Teresa (1983): Mujer, Falange y Franquismo. Madrid: Taurus.

GArcía Escudero, José María (1961a): Una encuesta de Film Ideal sobre “El séptimo sello". Film Ideal. 71:22. 
García Escudero, José María (1961b): Bergman y sus críticos. Film Ideal. 86:5-9.

García Escudero, José María (1978): La primera apertura. Diario de un Director General. La larga batalla de la censura en cine y teatro. Barcelona: Planeta.

González Ballesteros, Teodoro (1981): Aspectos jurídicos de la censura cinematográfica en España. Madrid: Editorial de la Universidad Complutense.

GraCIA, Jordi (1996): Estado y cultura. El despertar de una conciencia crítica bajo el franquismo (1940-1962). Toulouse: Presses Universitaires du Mirail.

Gracia, Jordi (2004): La resistencia silenciosa. Fascismo y cultura en España. Barcelona: Anagrama.

GUBERn, Román (1981): La censura: Función política y ordenamiento jurídico bajo el franquismo (1936-1975). Barcelona: Ediciones Península.

Gutiérrez Lanza, Camino (2000): Proteccionismo y censura durante la etapa franquista: Cine nacional, cine traducido y control estatal. In: Rosa RABADÁN, ed. Traducción y censura inglés-español: 1939-1985. Estudio preliminar. León: Universidad de León, 23-59.

Gutiérrez Lanza, Camino (2002): Spanish Film Translation and Cultural Patronage: The Filtering and Manipulation of Imported Material during Franco's Dictatorship. In: Maria Tymoczko y Edwin Gentzler, eds. Translation and Power. Amherst/Boston: University of Massachusetts Press, 141-159.

Hermans, Theo, ed. (1985): The Manipulation of Literature: Studies in Literary Translation. Londres: Croom Helm.

HurtLey, Jacqueline A. (2007): Tailoring the Tale. Inquisitorial Discourses, and Resistance, in the Early Franco Period (1940-1950). In: Francesca Billiani, ed. Modes of Censorship and Translation. Mánchester: St. Jerome, 61-92.

LEFEVERe, André (1992): Translation, Rewriting and the Manipulation of Literary Fame. Londres/ Nueva York: Routledge.

Martínez Bretón, Juan Antonio (1987): Influencia de la Iglesia Católica en la cinematografía española (1951-1962). Madrid: Harofarma.

Molist, Segismundo (1965): En el umbral de la vida (Nara [sic.] livet), de Ingmar Bergman. Film Ideal. 167:315-316.

Munday, Jeremy (2001): Introducing Translation Studies: Theories and Applications. Londres/ Nueva York: Routledge.

Pérez Lozano, José María. (1965): En el umbral de la vida. Cinestudio. 34:193.

Richmond, Kathleen (2003): Women and Spanish Fascism. The women's section of the Falange 1934-1959. Londres/Nueva York: Routledge.

Sevillano Calero, Francisco (2003): Propaganda y medios de comunicación en el Franquismo (1936-1951). Alicante: Publicaciones de la Universidad de Alicante.

SiCLIER, Jacques (1962): Ingmar Bergman. Madrid: Ediciones Rialp.

Söderbergh Widding, Astrid (2008): What should we believe?: Religious Motifs in Ingmar Bergman's Films. In: Maaret Koskinen, ed. Ingmar Bergman Revisited. Performance, Cinema and the Arts. Londres/Nueva York: Wallflower Press, 194-209.

Toury, Gideon (1980): In Search of a Theory of Translation. Tel Aviv: Tel Aviv University.

VANDAELE, Jeroen (2006): Estados de Gracia. Trasvases entre la semántica franquista y la poética de Billy Wilder (1946-1975). Tesis de doctorado no publicada. Lovaina: Katholieke Universiteit Leuven.

VAndaele, Jeroen (2007): Take Three. The National-Catholic Versions of Billy Wilder's Broadway Adaptations. In: Francesca Billiani, ed. Modes of Censorship and Translation. Mánchester: St. Jerome, 279-310.

VAndaele, Jeroen (2010): It Was What It Wasn't. Translation and Francoism. In: Chris Rundle y Kate Sturge, eds. Translation Under Fascism. Londres: Palgrave Macmillan, 84-116. 